\title{
Edge even graceful labeling of some graphs
}

\author{
Mohamed R. Zeen El Deen (1)
}

\author{
Correspondence: \\ mohamed.zeeneldeen@suezuniv.edu.e \\ Department of Mathematics, \\ Faculty of Science, Suez University, \\ Suez 43527, Egypt
}

\begin{abstract}
Edge even graceful labeling is a new type of labeling since it was introduced in 2017 by Elsonbaty and Daoud (Ars Combinatoria 130:79-96, 2017). In this paper, we obtained an edge even graceful labeling for some path-related graphs like $Y$ - tree, the double star $B_{n, m}$, the graph $\left\langle K_{1,2 n}: K_{1,2 m}\right\rangle$, the graph $P_{2 n-1} \odot K_{2 m}$, and double fan graph $F_{2, n}$. Also, we showed that some cycle-related graphs like the prism graph $\prod_{n}$, the graph $C_{n}\left(\frac{n}{2}\right)$, the flag $F L_{n}$, the graph $K_{2} \odot C_{n}$, the flower graph $F L(n)$, and the double cycle $\left\{C_{n, n}\right\}$ are edge even graphs.
\end{abstract}

Keywords: Edge-even graceful labeling, Flag graph $\mathrm{FL}_{n}$, Double fan graph $F_{2, n}$, Prism graph, The flower graph FL( $n)$

2010 Mathematics subject classification: 05 C 78, 05 C 76, 05 C 90, 05 C 99

\section{Introduction}

A graph labeling is an assignment of integers to the edges or vertices, or both, subject to certain condition. The idea of graph labelings was introduced by Rosa in [1]. Following this paper, other studies on different types of labelings (Odd graceful, Chordal graceful, Harmonious, edge odd graceful) introduced by many others [2-4]. A new type of labeling of a graph called an edge even graceful labeling has been introduced by Elsonbaty and Daoud [5]. They introduced some path- and cycle-related graphs which are edge even graceful.

Graph labelings give us useful models for a wide range of applications such as coding theory, X-ray, astronomy, radar, and communication network addressing.

Definition 1 [5] An edge even graceful labeling of a graph $G(V(G), E(G)$ ) with $p=$ $|V(G)|$ vertices and $q=|E(G)|$ edges is a bijective mapping $f$ of the edge set $E(G)$ into the set $\{2,4,6, \cdots, 2 q\}$ such that the induced mapping $f^{*}: V(G) \rightarrow\{0,2,4, \cdots, 2 q\}$, given by: $f^{*}(x)=\left(\sum_{x y \in E(G)} f(x y)\right) \bmod (2 k)$, is an injective function, where $k=\max (p, q)$. The graph that admits an edge even graceful labeling is called an edge even graceful graph.

In Fig. 1 , we present an edge even graceful labeling of the Peterson graph and the complete graph $K_{5}$.

\section{Edge even graceful for some path related graphs}

A Y- tree is a graph obtained from a path by appending an edge to a vertex of a path adjacent to an end point, and it is denoted by $Y_{n}$ where $n$ is the number of vertices in the tree.

(c) The Author(s). 2019 Open Access This article is distributed under the terms of the Creative Commons Attribution 4.0 International License (http://creativecommons.org/licenses/by/4.0/), which permits unrestricted use, distribution, and reproduction in any medium, provided you give appropriate credit to the original author(s) and the source, provide a link to the Creative Commons license, and indicate if changes were made. 

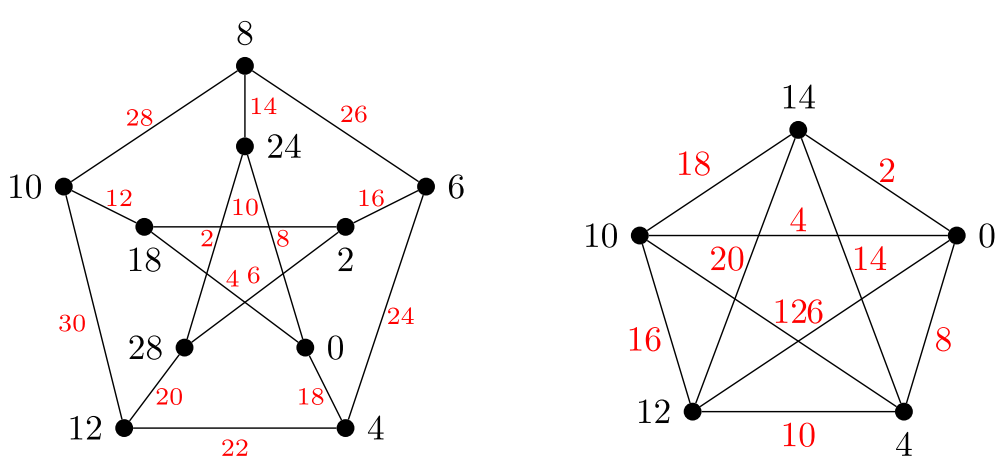

Fig. 1 An edge even graceful labeling of Peterson graph and the complete graph $K_{5}$

Lemma 1 The Y-tree $Y_{n}$ is an edge even graceful graph when $n$ is odd.

Proof The number of vertices of Y-tree $Y_{n}$ is $n$ and the number of edges is $n-1$. Let the vertices and the edges of $Y_{n}$ be given as in Fig. 2.

We define the mapping $f: E\left(Y_{n}\right) \rightarrow\{2,4, \cdots, 2 n-2\}$ as follows:

$$
\begin{array}{ll}
f\left(e_{i}\right)=2 i & \text { for } 1 \leq i \leq \frac{n+1}{2} \\
f\left(e_{\frac{n+3}{2}}\right)=n+5, & f\left(e_{\frac{n+5}{2}}\right)=n+3 \\
f\left(e_{i}\right)=2 i & \text { for } \quad \frac{n+7}{2} \leq i \leq n-1
\end{array}
$$

Then, the induced vertex labels are

$$
\begin{aligned}
f^{*}\left(v_{1}\right) & =2, \quad f^{*}\left(v_{2}\right)=2, \quad f^{*}\left(v_{3}\right)=12 \\
f^{*}\left(v_{i}\right) & =4 i-2 \quad \text { for } \quad 4 \leq i \leq \frac{n-1}{2} \\
f^{*}\left(v_{\frac{n+1}{2}}\right) & =\left[f\left(e_{\frac{n-1}{2}}\right)+f\left(e_{\frac{n+1}{2}}\right)\right] \bmod (2 n)=(2 n) \bmod (2 n)=0
\end{aligned}
$$

Similarly, $f^{*}\left(v_{\frac{n+3}{2}}\right)=6, \quad f^{*}\left(v_{\frac{n+5}{2}}\right)=8, \quad f^{*}\left(v_{\frac{n+7}{2}}\right)=10$,

$$
\begin{aligned}
& f^{*}\left(v_{i}\right)=(4 i-2) \bmod (2 n) \text { for } \frac{n+9}{2} \leq i \leq n-1, \\
& f^{*}\left(v_{n}\right)=2 n-2
\end{aligned}
$$

Clearly, all the vertex labels are even and distinct. Thus, Y-tree $Y_{n}$ is an edge even graceful graph when $n$ is odd.

Illustration: The edge even labeling of the graph $Y_{13}$ is shown in Fig. 3.

Double star is the graph obtained by joining the center of the two stars $K_{1, n}$ and $K_{1, m}$ with an edge, denoted by $B_{n, m}$. The graph $B_{n, m}$ has $p=n+m+2$ and $q=n+m+1$.

Lemma 2 The double star $B_{n, m}$ is edge even graceful graph when one ( $m$ or $\left.n\right)$ is an odd number and the other is an even number.

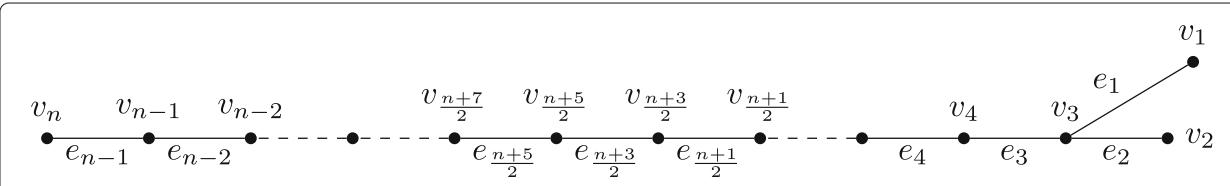

Fig. $2 Y_{n}$ with ordinary labeling 


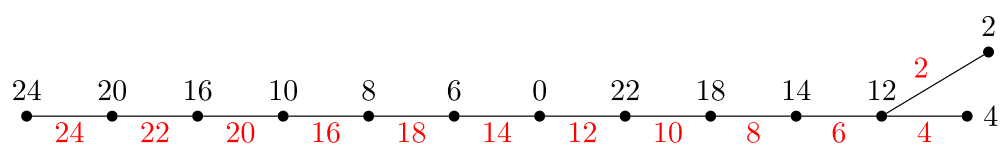

Fig. 3 The edge even labeling of the graph $Y_{13}$

Proof Without loss of generality, assume that $n$ is odd and $m$ is even. Let the vertex and edge symbols be given as in Fig. 4.

Define the mapping $f: E\left(B_{m, n}\right) \rightarrow\{2,4, \cdots, 2 q\}$ as follows:

$$
\begin{aligned}
& f\left(e_{i}\right)=2 i \\
& \text { for } 1 \leq i \leq \frac{n+1}{2} \\
& f\left(E_{i}\right)=2 p-2(i+1) \quad \text { for } \quad 1 \leq i \leq \frac{n-1}{2} \\
& f\left(a_{i}\right)=m+2 i \quad \text { for } 1 \leq i \leq \frac{m}{2} \\
& f\left(b_{i}\right)=2 p-[m+2 i] \quad \text { for } 1 \leq i \leq \frac{m}{2} \\
& f(w)=2 p-2
\end{aligned}
$$

We realize the following:

$$
\begin{aligned}
f\left(E_{i}\right)+f\left(e_{i+1}\right) & \equiv 0 \bmod (2 p) \quad \text { for } i=1,2, \cdots, \frac{n-1}{m^{2}} \\
f\left(a_{i}\right)+f\left(b_{i}\right) & \equiv 0 \bmod (2 p) \text { for } j=1,2, \cdots, \frac{m^{2}}{2}
\end{aligned}
$$

So, the vertex labels will be

$$
\begin{gathered}
f^{*}(u)=\left[f\left(e_{1}\right)+f(w)\right] \bmod (2 p)=0 \text { and } \\
f^{*}(v)=f(w)=(2 p-2) \bmod (2 p)=2 p-2
\end{gathered}
$$

Also, each pendant vertex takes the labels of its incident edge which are different from the labels of the vertices $U$ and $v$.

The graph $\left\langle K_{1, n}: K_{1, m}\right\rangle$ is obtained by joining the center $v_{1}$ of the star $K_{1, n}$ and the center $v_{2}$ of the another star $K_{1, m}$ to a new vertex $u$, so the number of vertices is $p=n+m+3$ and the number of edges is $q=n+m+2$.

Lemma 3 The graph $\left\langle K_{1,2 n}: K_{1,2 m}\right\rangle$ is an edge even graceful graph.

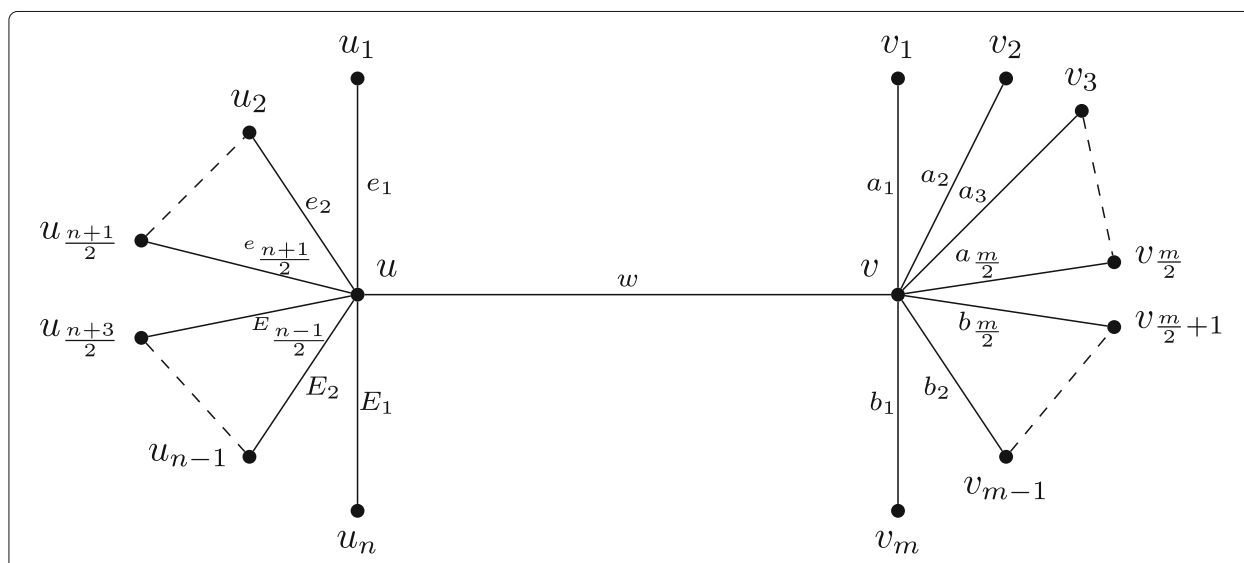

Fig. $4 B_{m, n}$ with ordinary labeling 


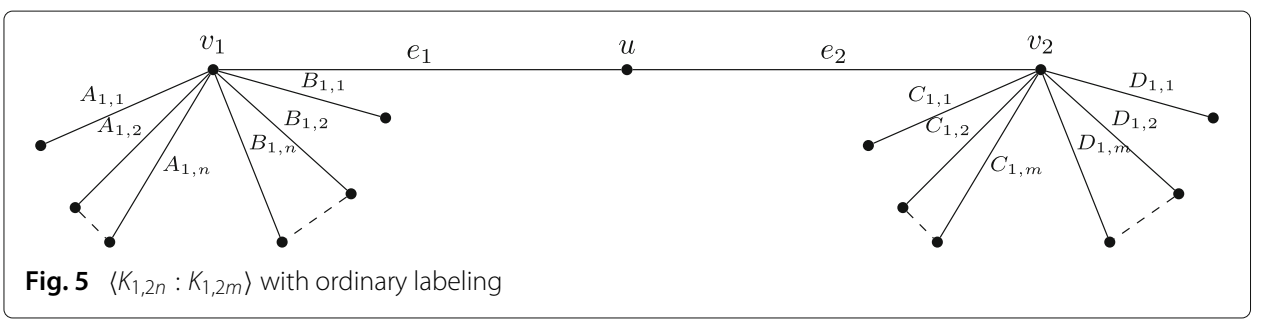

Proof Let the vertex and edge symbols be given as in Fig. 5 .

Define the mapping $f: E(G) \rightarrow\{2,4, \cdots, 2 p\}$ as follows:

$$
\begin{array}{lrl}
f\left(e_{1}\right)=m n+2 & & f\left(e_{2}\right)=2 p-(m n+2) \\
f\left(A_{i}\right)=2 i & & \text { for } i=1,2, \cdots, n \\
f\left(B_{i}\right)=2 p-2 i & \text { for } i=1,2, \cdots, n \\
f\left(C_{i}\right)=2 n+2 i & \text { for } i=1,2, \cdots, m \\
f\left(B_{i}\right)=2 p-[2 n+2 i] & \text { for } i=1,2, \cdots, m
\end{array}
$$

We can see the following:

$$
\begin{array}{ll}
f\left(A_{i}\right)+f\left(B_{i}\right) \equiv 0 \bmod (2 p) & \text { for } i=1,2, \cdots, n \\
f\left(C_{i}\right)+f\left(D_{i}\right) \equiv 0 \bmod (2 p) & \text { for } j=1,2, \cdots, m
\end{array}
$$

So, the vertex labels will be

$$
\begin{aligned}
f^{*}(u) & =\left[f\left(e_{1}\right)+f\left(e_{2}\right)\right] \bmod (2 p)=0, \\
f^{*}\left(v_{1}\right) & =f\left(e_{1}\right)=m n+2 \text { and } \\
f^{*}\left(v_{2}\right) & =f\left(e_{2}\right)=2 p-[2 n+2 i]
\end{aligned}
$$

which are even and distinct from each pendant vertices. Thus, the graph $\left\langle K_{1,2 n}: K_{1,2 m}\right\rangle$ is an edge even graceful graph.

Lemma 4 The corona [6] $P_{3} \odot \overline{K_{2 m}}$ is an edge even graceful graph.

Proof In this graph $p=6 m+3$ and $q=6 m+2$. Let the vertex and edge symbols be given as in Fig. 6.

We can define the mapping $f: E\left(P_{3} \odot \overline{K_{2 m}}\right) \rightarrow\{2,4, \cdots, 2 q\}$ as follows:

$$
\begin{aligned}
f\left(e_{i}\right) & =6 m+2 i & & \text { for } i=1,2 \\
f\left(A_{i j}\right) & =2(i-1) m+2 j & & \text { for } i=1,2, \cdots, m \\
f\left(B_{i j}\right) & =2 p-[2(i-1) m+2 j] & & \text { for } i=1,2, \cdots, m
\end{aligned}
$$

It is clear that $\quad f\left(A_{i j}\right)+f\left(B_{i j}\right) \equiv 0 \bmod (2 p) \quad$ for $j=1,2, \cdots, m$

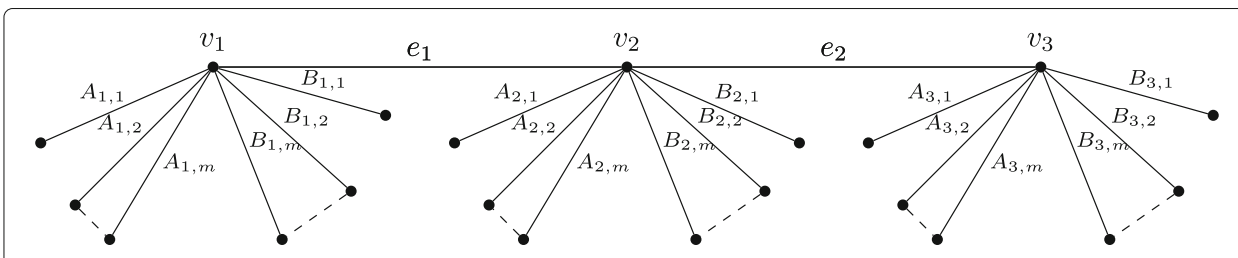

Fig. $6 \quad P_{3} \odot \overline{K_{2 m}}$ with ordinary labeling 


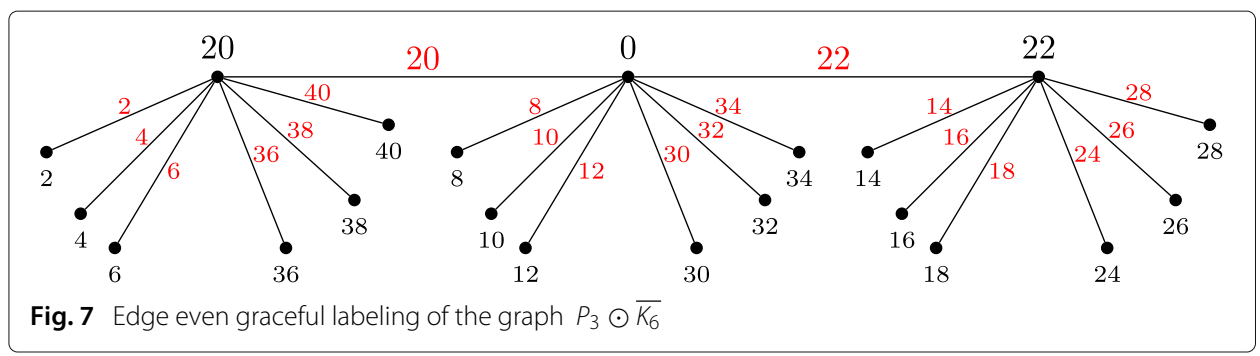

So the vertex labels will be,

$$
\begin{aligned}
& f^{*}\left(v_{1}\right)=f\left(e_{1}\right)=6 m+2, \quad f^{*}\left(v_{3}\right)=f\left(e_{2}\right)=6 m+4 \quad \text { and } \\
& f^{*}\left(v_{2}\right)=\left[f\left(e_{1}\right)+f\left(e_{2}\right)\right] \bmod (2 p)=[(6 m+2)+(6 m+4)] \bmod (2 p)=0
\end{aligned}
$$

Therefore, all the vertices are even and distinct which complete the proof.

Illustration: The edge even labeling of the graph $P_{3} \odot \overline{K_{6}}$ is shown in Fig. 7 .

The generalization of the previous result is presented in the following theory

Theorem 1 The graph $P_{2 n-1} \odot \overline{K_{2 m}}$ is an edge even graceful graph.

Proof In this graph, $p=4 n m+2(n-m)-1$ and $q=4 n m+2(n-m)-2$. The middle vertex in the path $P_{2 n-1}$ will be $v_{n}$, and we start the labeling from this vertex. Let the vertex and edge symbols be given as in Fig. 8 .

Define the mapping $f: E(G) \rightarrow\{2,4, \cdots, 2 q\}$ by the following arrangement

$$
\begin{aligned}
& f\left(e_{i}\right)=2^{i} \quad \text { for } i=1,2, \cdots, n-1 \\
& f\left(b_{i}\right)=2 p-2^{i} \quad \text { for } i=1,2, \cdots, n-1
\end{aligned}
$$

$f\left(A_{i j}\right) \quad$ will take any number from the reminder set of the labeling not contains $2^{i}$ nor $2 p-2^{i}$ for $j=1,2, \cdots, m$ and

$$
f\left(D_{i j}\right)=2 p-\left[f\left(A_{i j}\right)\right] \quad \text { for } j=1,2, \cdots, m .
$$

It is clear that $\left[f\left(A_{i j}\right)+f\left(D_{i j}\right)\right] \bmod (2 p) \equiv 0 \bmod (2 p) \quad$ for $j=1,2, \cdots, m$.

So, the vertex labels will be $f^{*}\left(v_{n}\right)=\left[f\left(e_{1}\right)+f\left(b_{1}\right)\right] \bmod (2 p) \equiv 0 \bmod (2 p)$,

For any vertex $v_{k}$ when $k<n$, let $k=n-i$ and $i=1,2, \cdots, n-2$

$$
f^{*}\left(v_{k}\right)=f^{*}\left(v_{n-i}\right)=\left\{\begin{array}{l}
{\left[f\left(e_{i}\right)+f\left(b_{i+1}\right)\right] \bmod (2 p)=f\left(b_{i}\right) \text { if } i \text { is odd }} \\
{\left[f\left(b_{i}\right)+f\left(e_{i+1}\right)\right] \bmod (2 p)=f\left(e_{i}\right) \text { if } i \text { is even }}
\end{array}\right.
$$

When $k>n$, let $k=n+i$ and $i=1,2, \cdots, n-2$

$$
f^{*}\left(v_{k}\right)=f^{*}\left(v_{n+i}\right)=\left\{\begin{array}{l}
{\left[f\left(b_{i}\right)+f\left(e_{i+1}\right)\right] \bmod (2 p)=f\left(e_{i}\right) \text { if } i \text { is odd }} \\
{\left[f\left(e_{i}\right)+f\left(b_{i+1}\right)\right] \bmod (2 p)=f\left(b_{i}\right) \text { if } i \text { is even }}
\end{array}\right.
$$

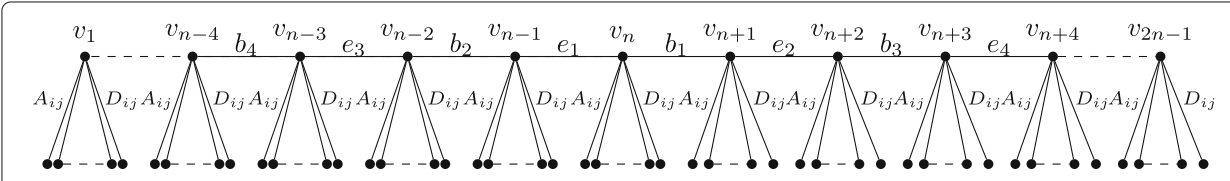

Fig. $8 P_{2 n-1} \odot \overline{K_{2 m}}$ with ordinary labeling 


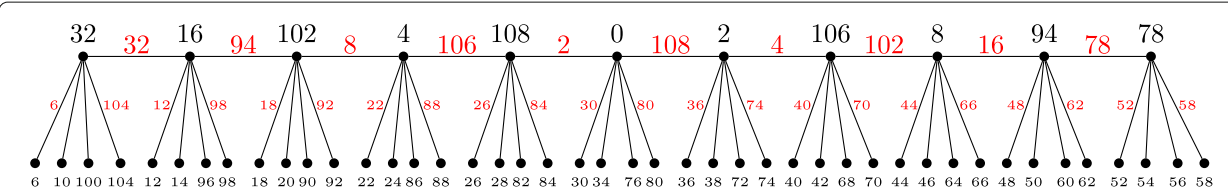

Fig. 9 Edge even graceful labeling of the graph $P_{11} \odot \overline{K_{4}}$

The pendant vertices $v_{1}$ and $v_{2 n-1}$ of the path $P_{2 n-1}$ will take the labels of its pendant edges of $P_{2 n-1}$,i.e.,

If $n$ is even, then $f^{*}\left(v_{1}\right)=f\left(e_{n-1}\right)$, and $f^{*}\left(v_{2 n-1}\right)=f\left(b_{n-1}\right)$

If $n$ is odd, then $f^{*}\left(v_{1}\right)=f\left(b_{n-1}\right)$, and $f^{*}\left(v_{2 n-1}\right)=f\left(e_{n-1}\right)$

Then, the labels of the vertices of the path $P_{2 n-1}$ takes the labels of the edges of the path $P_{2 n-1}$, and each pendant vertex takes the labels of its incident edge. Then, there are no repeated vertex labels, which complete the proof.

Illustration: The graph $P_{11} \odot \overline{K_{4}}$ labeled according to Theorem 1 is presented in Fig. 9. A double fan graph $F_{2, n}$ is defined as the graph join $\overline{K_{2}}+P_{n}$ where $\overline{K_{2}}$ is the empty graph on two vertices and $P_{n}$ be a path of length $n$.

Theorem 2 The double fan graph $F_{2, n}$ is an edge even graceful labeling when $n$ is even.

Proof In the graph $F_{2, n}$ we have $p=n+2$ and $q=3 n-1$. Let the graph $F_{2, n}$ be given as indicated in Fig. 10.

Define the edge labeling function $f: E\left(F_{2, n}\right) \longrightarrow\{2,4, \cdots, 6 n-2\}$ as follows:

$$
\begin{aligned}
& f\left(a_{i}\right)=2 i ; \quad i=1,2, \cdots n \\
& f\left(b_{i}\right)=2 q-2 i=6 n-2(i+1) ; \quad i=1,2, \cdots n \\
& f\left(e_{i}\right)= \begin{cases}2 n+2 i & \text { if } 1 \leq i<\frac{n}{2} \\
6 n-2 & \text { if } i=\frac{n}{2} \\
2 n+2(i-1) & \text { if } \frac{n}{2}<i \leq n-1\end{cases}
\end{aligned}
$$

Hence, the induced vertex labels are

$$
f^{*}(u)=\left(\sum_{i=1}^{n}\left(f\left(a_{i}\right)\right)\right) \bmod (6 n-2)=\left(\sum_{i=1}^{n}(2 i)\right) \bmod (6 n-2)=\left(n^{2}+n\right) \bmod (6 n-2)
$$

$f^{*}(v)=\left(\sum_{i=1}^{n}\left(f\left(b_{i}\right)\right)\right) \bmod (6 n-2)=\left(\sum_{i=1}^{n}(2 q-2 i)\right) \bmod (6 n-2)=$ $\left(-n^{2}-n\right) \bmod (6 n-2)$

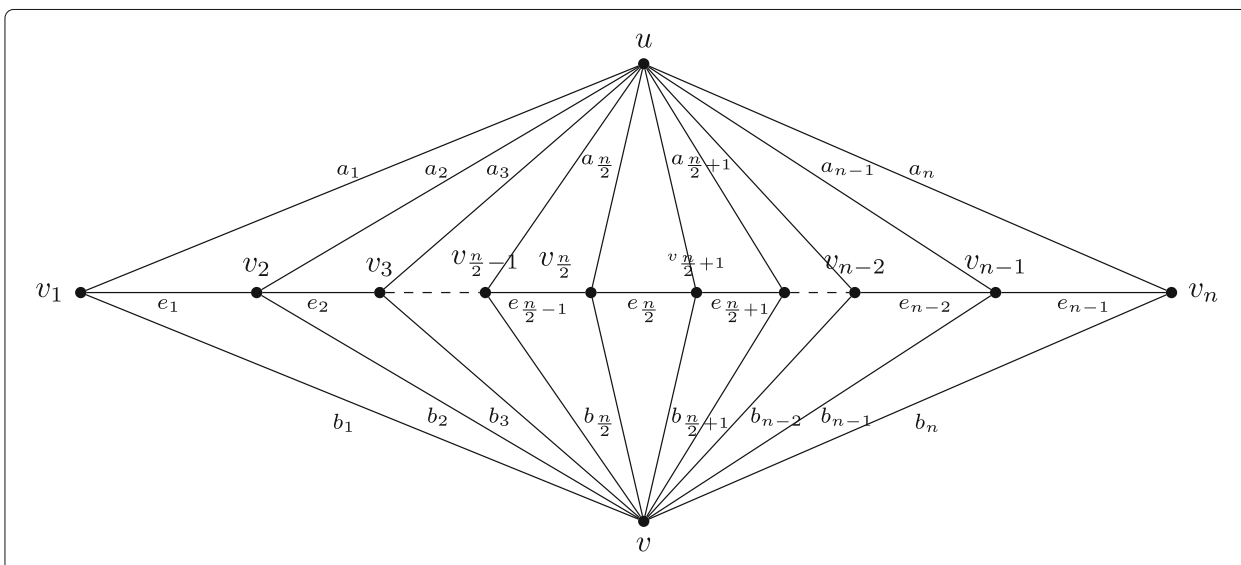

Fig. $10 \quad F_{2, n}$ with ordinary labeling 
$f^{*}\left(v_{i}\right)=\left[\sum_{i=1}^{n}\left(f\left(a_{i}\right)+f\left(b_{i}\right)+f\left(e_{i}\right)+f\left(e_{i-1}\right)\right)\right] \bmod (6 n-2)=(4 n+4 i-2) \bmod (6 n-$ 2) , $2 \leq i \leq \frac{n}{2}-1$

$f^{*}\left(v_{i}\right)=\left[\sum_{i=1}^{n}\left(f\left(a_{i}\right)+f\left(b_{i}\right)+f\left(e_{i}\right)+f\left(e_{i-1}\right)\right)\right] \bmod (6 n-2)=(4 n+4 i-6) \bmod (6 n-$ 2), $\frac{n}{2}+2 \leq i \leq n-1$

Since $\left[f\left(a_{i}\right)+f\left(b_{i}\right)\right] \bmod (6 n-2)=0$, we see that

$$
\begin{aligned}
& f^{*}\left(v_{1}\right)=f\left(e_{1}\right)=2 n+2, \\
& f^{*}\left(v_{n}\right)=f\left(e_{n-1}\right)=4 n-4, \\
& f^{*}\left(v_{\frac{n}{2}}\right)=f\left(e_{\frac{n}{2}-1}\right)=3 n-2 \text { and } \\
& f^{*}\left(v_{\frac{n}{2}+1}\right)=f\left(e_{\frac{n}{2}}\right)=3 n
\end{aligned}
$$

Thus, the set of vertices $v_{1}, v_{2}, v_{3}, \cdots, v_{\frac{n}{2}-1}, v_{\frac{n}{2}}, v_{\frac{n}{2}+1}, v_{\frac{n}{2}+2}, v_{\frac{n}{2}+3}, \cdots, v_{n-2}, v_{n-1}, v_{n}$ are labeled by $2 n+2,4 n+6,4 n+10, \cdots, 6 n-6,3 n-2,3 n, 4,8, \cdots, 2 n-12,2 n-8,4 n-4$ respectively.

Clearly, $f^{*}(u)$ and $f^{*}(v)$ are different from all the labels of the vertices. Hence $F_{2, n}$ is an edge even graceful when $n$ is even.

Illustration: The double fan $F_{2,10}$ labeled according to Theorem 2 is presented in Fig. 11.

\section{Edge even graceful for some cycle related graphs}

Definition 2 For $n \geq 4$, a cycle ( of order $n$ ) with one chord is a simple graph obtained from an $n$-cycle by adding a chord. Let the $n$-cycle be $v_{1} v_{2} \cdots v_{n} v_{1}$. Without loss of generality, we assume that the chord joins $v_{1}$ with any one $v_{i}$, where $3 \leq i \leq n-1$. This graph is denoted by $C_{n}(i)$.

Lemma 5 The graph $C_{n}\left(\frac{n}{2}\right)$ is an edge even graceful graph if $n$ is even.

Proof Let $\left\{v_{1}, v_{2}, \cdots, v_{\frac{n}{2}-1}, v_{\frac{n}{2}}, v_{\frac{n}{2}+1}, \cdots, v_{n}\right\}$ be the vertices of the graph $C_{n}\left(\frac{n}{2}\right)$, and the edges are $e_{i}=\left(v_{i} v_{i+1}\right)$ for $i \leq i \leq n-1$ and the chord $e_{0}=\left(v_{1} v_{\frac{n}{2}}\right)$ connecting the vertex $v_{1}$ with $v_{\frac{n}{2}}$ as in Fig. 12 .

Here, $p=n$ and $q=n+1$, so $2 k=2 q=2 n+2$; first, we label the edges as follows:

$$
f\left(e_{i}\right)=2 i+2 ; \quad i=0,1,2, \cdots n
$$

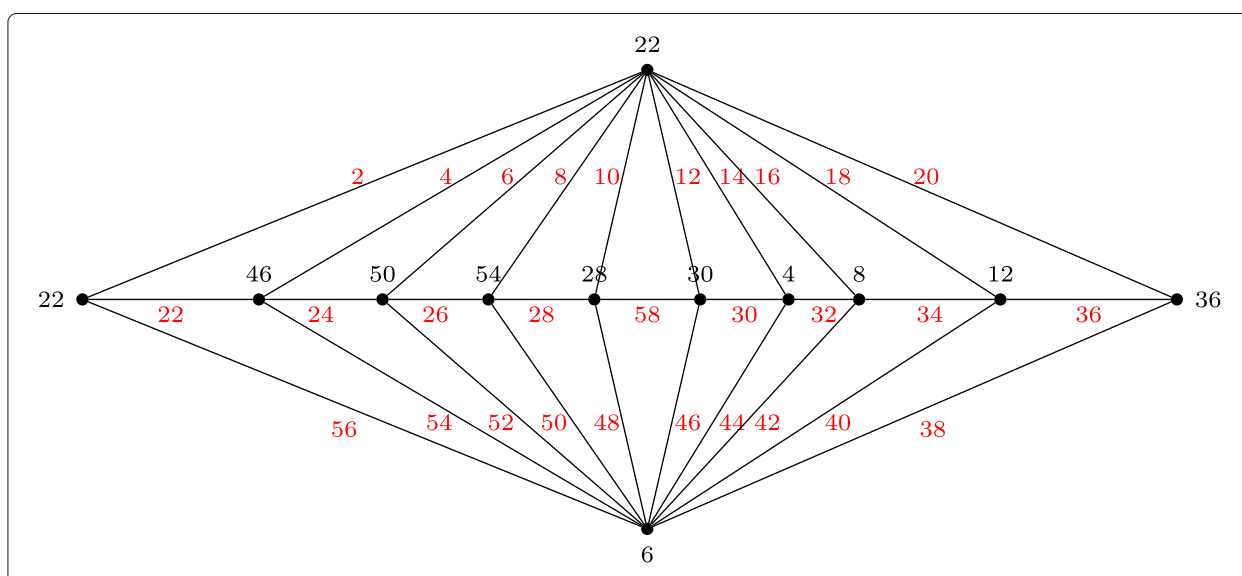

Fig. 11 Edge even graceful labeling of the double fan $F_{2,10}$ 


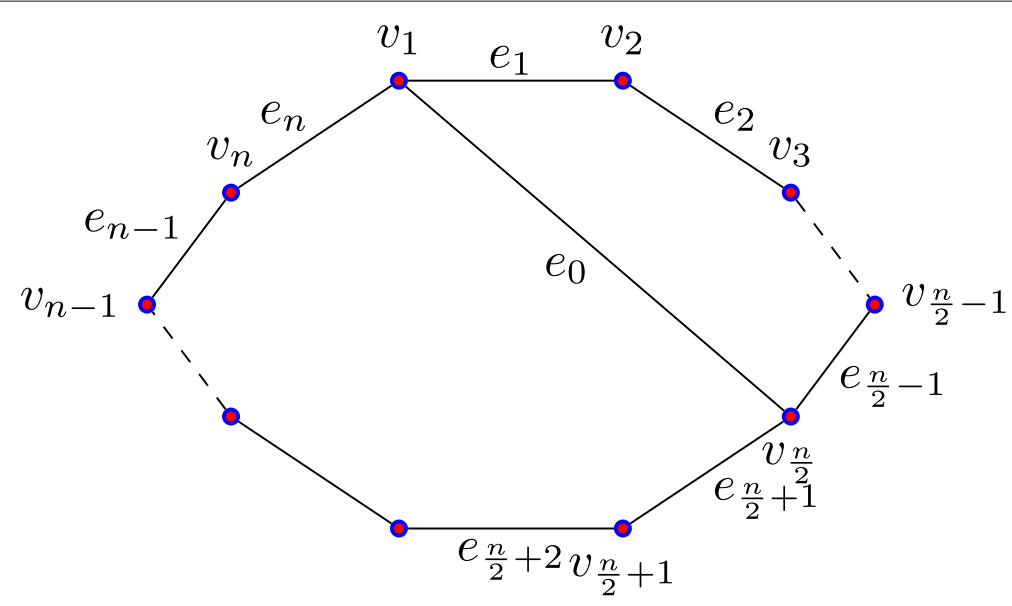

Fig. $12 C_{n}\left(\frac{n}{2}\right)$ with ordinary labeling

Then, the induced vertex labels are as follows:

$$
\begin{aligned}
& f^{*}\left(v_{1}\right)=\left[f\left(e_{0}\right)+f\left(e_{1}\right)+f\left(e_{n}\right)\right] \bmod (2 n+2)=(2+4+2 n+2) \bmod (2 n+2)=6, \\
& f^{*}\left(v_{\frac{n}{2}}\right)=\left[f\left(e_{0}+f\left(e_{\frac{n}{2}}\right)+f\left(e_{\frac{n}{2}-1}\right)\right] \bmod (2 n+2)=(2 n+4) \bmod (2 n+2)=2\right.
\end{aligned}
$$

for any other vertex $v_{i}, \quad i \neq 1, \frac{n}{2}$

$$
f^{*}\left(v_{i}\right)=f\left(e_{i}\right)+f\left(e_{i-1}\right)=(4 n+4) \bmod (2 n+2)=(4 i+2) \bmod (2 n+2)
$$

Hence, the labels of the vertices $v_{0}, v_{1}, v_{2}, \cdots, v_{\frac{n}{2}-1}, v_{\frac{n}{2}}, v_{\frac{n}{2}+1}, \cdots v_{n}$ are $6,10,14, \cdots, 2 n-2,2,4, \cdots, 2 n$ respectively, which are even and distinct. So, the graph $C_{n}\left(\frac{n}{2}\right)$ is an edge even graceful graph if $n$ is even.

Definition 3 Let $C_{n}$ denote the cycle of length $n$. The flag $F L_{n}$ is obtained by joining one vertex of $C_{n}$ to an extra vertex called the root, in this graph $p=q=n+1$.

Lemma 6 The flag graph $F L_{n}$ is edge even graceful graph when $n$ is even.

Proof Let $\left\{v_{1}, v_{2}, \cdots, v_{n}\right\}$ be the vertices of the cycle $C_{n}$ and the edges are $e_{i}=$ $\left(v_{i} v_{i+1}\right)$ for $1 \leq i \leq n$ and the edge $e=\left(v_{1} v_{0}\right)$ connecting the vertex $v_{1}$ with $v_{0}$ as in Fig. 13.

First, we label the edges as follows:

$$
f\left(e_{i}\right)=2 i+2 ; \quad i=0,1,2, \cdots n
$$

Then, the induced vertex labels are as follows $f^{*}\left(v_{0}\right)=f\left(e_{0}\right)=2$,

$$
\begin{aligned}
f^{*}\left(v_{1}\right) & =\left[f\left(e_{0}\right)+f\left(e_{1}\right)+f\left(e_{n}\right)\right] \bmod (2 n+2)=(2+4+2 n+2) \bmod (2 n+2)=6 \\
f^{*}\left(v_{i}\right) & =\left[f\left(e_{i}\right)+f\left(e_{i-1}\right)\right] \bmod (2 n+2)=(4 i+2) \bmod (2 n+2) \quad i=2,3, \cdots, n
\end{aligned}
$$

Hence, the labels of the vertices $v_{0}, v_{1}, v_{2}, \cdots, v_{\frac{n}{2}-1}, v_{\frac{n}{2}}, v_{\frac{n}{2}+1}, \cdots v_{n}$ will be $2,6,10,14, \cdots, 2 n-2,0,4, \cdots, 2 n$ respectively.

Lemma 7 The graph $K_{2} \odot C_{n}$ is edge even graceful graph when $n$ is odd. 


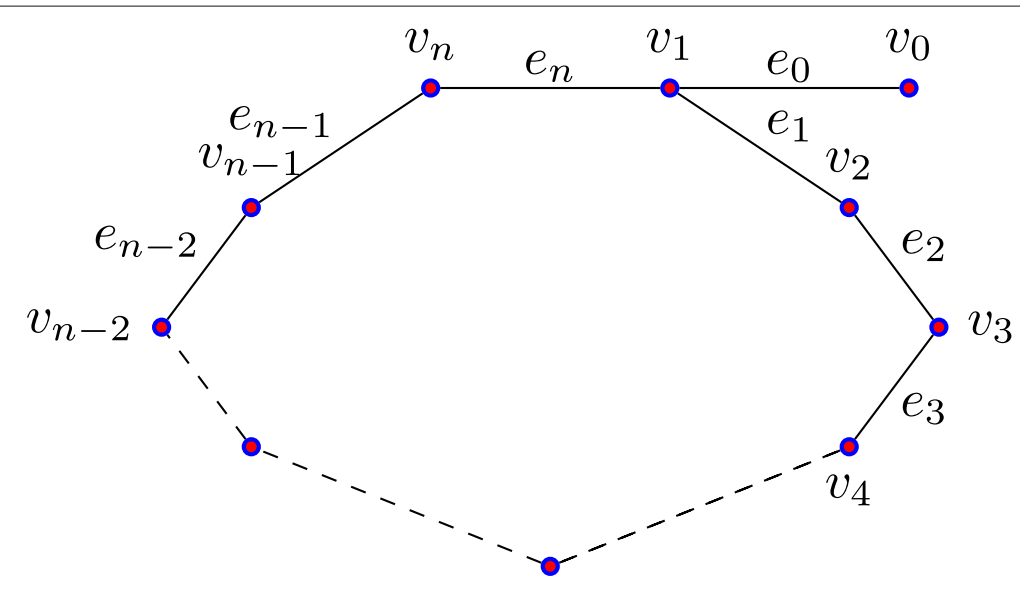

Fig. $13 \mathrm{Fl}$ with ordinary labeling

Proof Let $\left\{v_{1}, v_{2}, \cdots, v_{n}, v_{1}^{\prime}, v_{2}^{\prime}, \cdots, v_{n}^{\prime}\right\}$ be the vertices of the graph $K_{2} \odot C_{n}$ and the edges are $\left\{e_{1}, e_{2}, \cdots, e_{n}, e_{1}^{\prime}, e_{2}^{\prime}, \cdots, e_{n}^{\prime}\right\}$ as shown in Fig. 14. Here, $p=2 n$ and $q=2 n+1$, so $2 k=4 n+2$.

First, we label the edges as follows:

$$
\begin{array}{lrl}
f\left(e_{i}\right)=2 i ; & 1 \leq i \leq n+1 \\
f\left(e_{i}^{\prime}\right)=2 n+2(i+1) ; & 1 \leq i \leq n
\end{array}
$$

We can see that $\left[f\left(e_{n}\right)+f\left(e_{n+1}\right)\right] \bmod (2 q)=(4 n+2) \bmod (4 n+2) \equiv 0$

Then, the induced vertex labels are as follows

$$
\begin{aligned}
& f^{*}\left(v_{i}\right)=[\left.f\left(e_{i}\right)+f\left(e_{i+1}\right)\right] \bmod (4 n+2) \quad 1 \leq i \leq n-1 \\
&= {[6+4(i-1)] \bmod (4 n+2), \quad 1 \leq i \leq n-1 } \\
& f^{*}\left(v_{i}^{\prime}\right)=[\left.f\left(e_{i}^{\prime}\right)+f\left(e_{i+1}^{\prime}\right)\right] \bmod (4 n+2)=[8+4(i-1)] \bmod (4 n+2), \quad 1 \leq i<n \\
& f^{*}\left(v_{n}\right)=\left[f\left(e_{1}\right)+f\left(e_{n}\right)+f\left(e_{n+1}\right)\right] \bmod (4 n+2)=f\left(e_{1}\right) \bmod (4 n+2) \equiv 2 \\
& f^{*}\left(v_{n}^{\prime}\right)=\left[f\left(e_{1}^{\prime}\right)+f\left(e_{n+1}\right)+f\left(e_{n}^{\prime}\right)\right] \bmod (4 n+2) \equiv 4
\end{aligned}
$$

Clearly, the vertex labels are all even and distinct. Hence, the graph $K_{2} \odot C_{n}$ is edge even graceful for odd $n$.

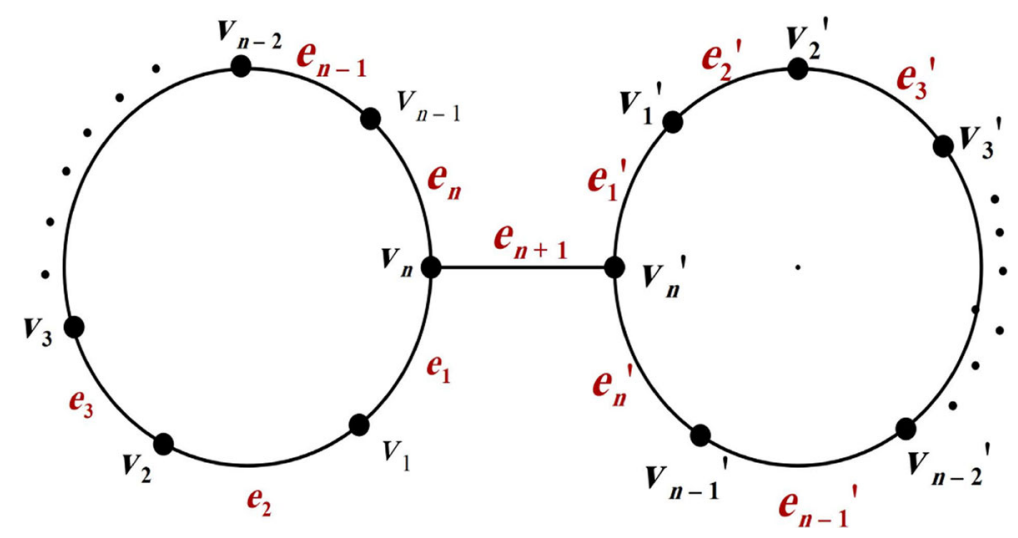

Fig. 14 The graphs $K_{2} \odot C_{n}$ with ordinary labeling 


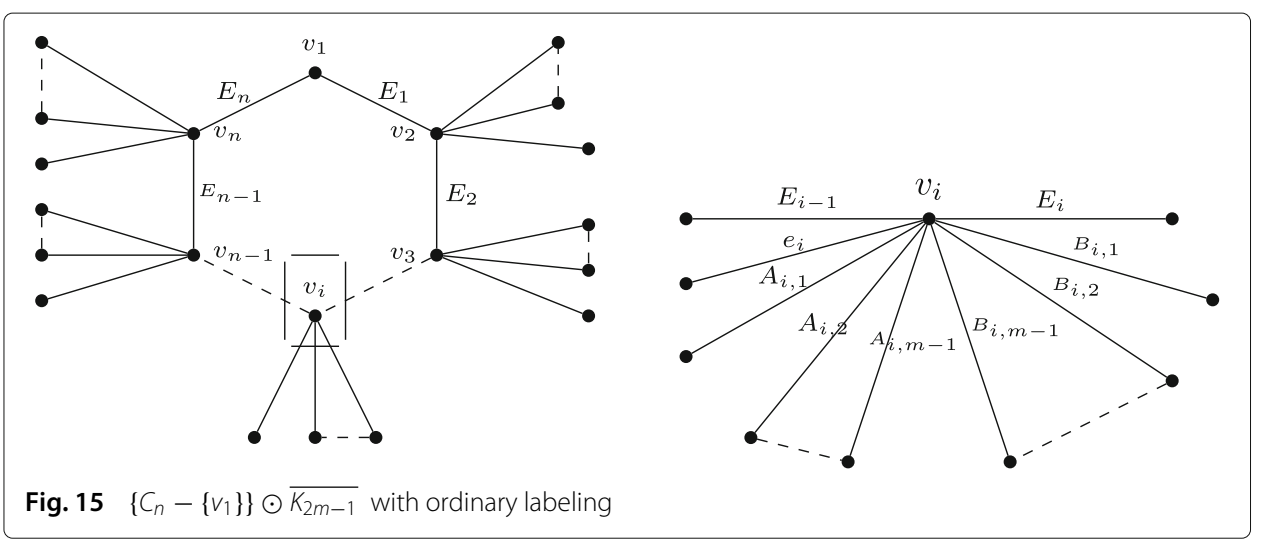

Let $C_{n}$ denote the cycle of length $n$. Then, the corona of all vertices of $C_{n}$ except one vertex $\left\{v_{1}\right\}$ with the complement graph $\overline{K_{2 m-1}}$ is denoted by $\left\{C_{n}-\left\{v_{1}\right\}\right\} \odot \overline{K_{2 m-1}}$, in this graph $p=q=2 m(n-1)+1$.

Lemma 8 The graph $\left\{C_{n}-\left\{v_{1}\right\}\right\} \odot \overline{K_{2 m-1}}$ is an edge even graceful graph.

Proof Let the vertex and edge symbols be given as in Fig. 15.

Define the mapping $f: E(G) \rightarrow\{2,4, \cdots, 2 q\}$ as follows:

$$
\begin{array}{rlrl}
f\left(E_{i}\right) & =2(i-1) m+2 & & \text { for } i=1,2, \cdots, n-1 \\
f\left(E_{n}\right) & =2 q & & \\
f\left(e_{i+1}\right) & =2 q-[2(i-1) m+2] & & \text { for } \quad i=1,2, \cdots, n-1 \\
f\left(A_{i j}\right) & =2(i-1) m+2 j+2 & \text { for } \quad j=1,2, \cdots, m-1 \\
f\left(B_{i j}\right) & =2 q-[2(i-1) m+2 j+2] & \text { for } j=1,2, \cdots, m-1
\end{array}
$$

We realize the following:

$$
\left[f\left(A_{i j}\right)+f\left(B_{i j}\right)\right] \bmod (2 q) \equiv 0 \bmod (2 q) \quad \text { for } j=1,2, \cdots, m-1
$$

Also, $\left[f\left(E_{i-1}\right)+f\left(e_{i}\right)\right] \bmod (2 q) \equiv 0 \bmod (2 q) \quad$ for $i=2,3, \cdots, n$

So, verifying the vertex labels, we get that,

$$
\begin{aligned}
f^{*}\left(v_{1}\right) & =\left[f\left(E_{1}\right)+f\left(E_{n}\right)\right] \bmod (2 q)=(2+2 q) \bmod (2 q)=2, \\
f^{*}\left(v_{i}\right) & =\left[\sum_{j=1}^{m-1} f\left(A_{i j}\right)+\sum_{j=1}^{m-1} f\left(B_{i j}\right)+f\left(E_{i}\right)+f\left(E_{i-1}\right)+f\left(e_{i}\right)\right] \bmod (2 q) \quad i=2,3, \cdots, n \\
& =f\left(E_{i}\right) \bmod (2 q)=2(i-1) m+2 \bmod (2 q), \quad i=2,3, \cdots, n
\end{aligned}
$$

Hence, the labels of the vertices $v_{1}, v_{2}, \cdots, v_{n}$ takes the label of the edges of the cycles and each of the pendant vertices takes the label of its edge, so they are all even and different numbers.

Illustration: In Fig. 16, we present an edge even graceful labeling of the graph $\left\{C_{6}-\right.$ $\left.\left\{v_{1}\right\}\right\} \odot \overline{K_{3}}$.

Lemma 9 The double cycle graph $\left\{C_{n, n}\right\}$ is an edge even graceful graph when $n$ is odd.

Proof Here, $p=n$ and $q=2 n$. Let the vertex and edge symbols be given as in Fig. 17 . 


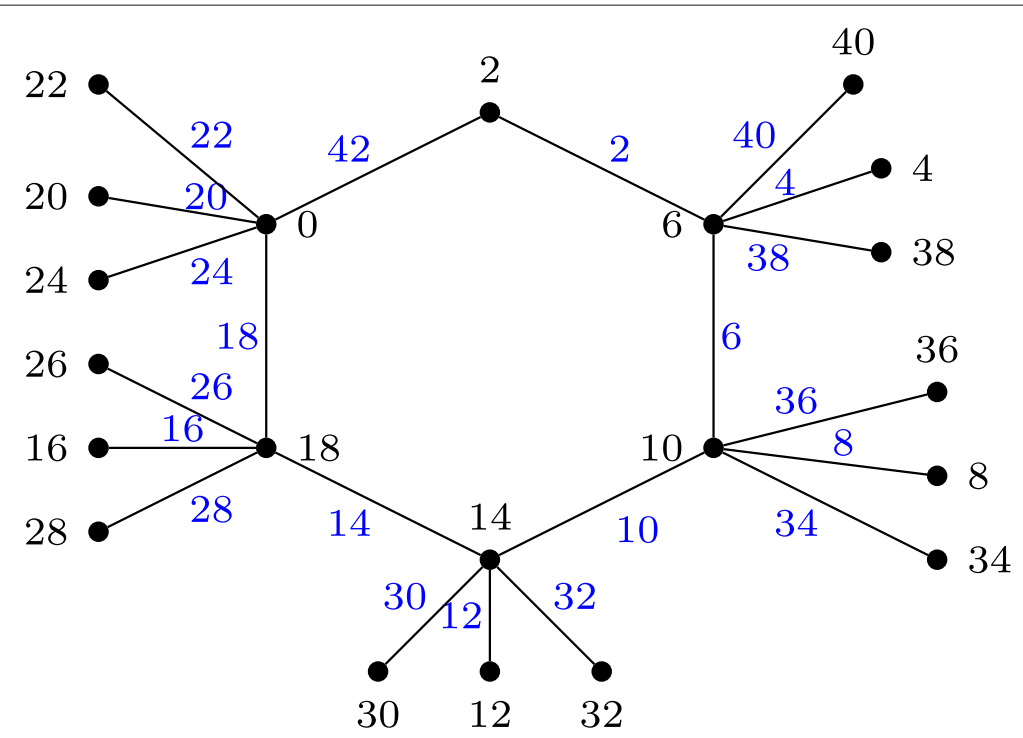

Fig. $16\left\{C_{6}-\left\{V_{1}\right\}\right\} \odot \overline{K_{3}}$

Define the mapping $f: E(G) \rightarrow\{2,4, \cdots, 4 n\}$ by

$f\left(e_{i}\right)=2 i \quad$ for $i=1,2, \cdots, n$. So, the vertex labels will be

$f^{*}\left(v_{1}\right)=\left[f\left(e_{1}\right)+f\left(e_{n}\right)+f\left(e_{n+1}\right)+f\left(e_{2 n}\right)\right] \bmod (4 n)=4$

$$
\begin{aligned}
f^{*}\left(v_{i}\right) & =\left[f\left(e_{i}\right)+f\left(e_{i-1}\right)+f\left(e_{i+n}\right)+f\left(e_{i+n-1}\right)\right] \bmod (4 n) \quad i=2,, \cdots, n \\
& =(8 i-4) \bmod (4 n) \quad i=2,3, \cdots, n
\end{aligned}
$$

Hence, the labels of the vertices $v_{1}, v_{2}, v_{3}, \cdots, v_{\frac{n+1}{2}}, v_{\frac{n+3}{2}}, \cdots, v_{n}$ will be $4,12,20, \cdots, 0,8, \cdots, 4 n-4$

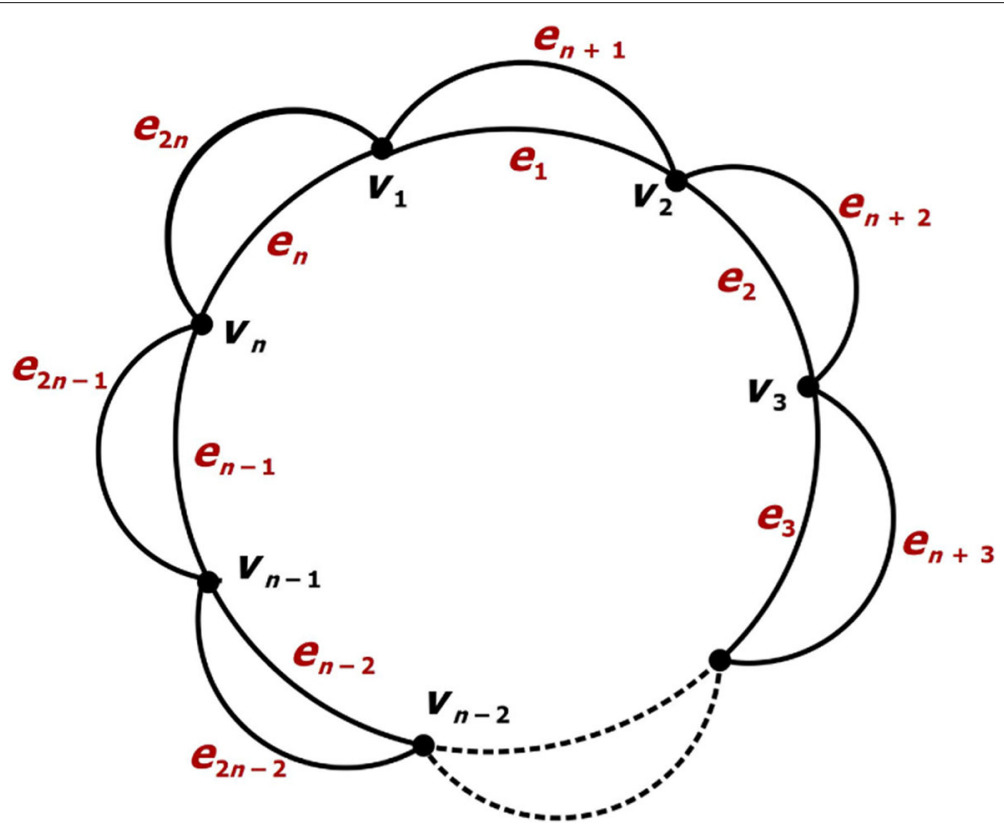

Fig. $17\left\{C_{n, n}\right\}$ with ordinary labeling 
The prism graph $\prod_{n}$ is the cartesian product $C_{n} \square K_{2}$ of a cycle $C_{n}$ by an edge $K_{2}$, and an $n$-prism graph has $p=2 n$ vertices and $q=3 n$ edges.

Theorem 3 The prism graph $\prod_{n}$ is edge even graceful graph.

Proof In the prism graph $\prod_{n}$ we have two copies of the cycle $C_{n}$, let the vertices in one copy be $v_{1}, v_{2}, \cdots, v_{n}$ and the vertices on the other copy be $v_{1}^{\prime}, v_{2}^{\prime}, \cdots, v_{n}^{\prime}$. In $\prod_{n}$, the edges will be

$v_{i} v_{i+1}, \quad v_{i}^{\prime} v_{i+1}^{\prime}, \quad$ and $v_{i} v_{i}^{\prime}$. Let the vertex and edge symbols be given as in Fig. 18.

Define the mapping $f: E\left(\prod_{n}\right) \rightarrow\{2,4, \cdots, 6 n\}$ by

$$
\begin{array}{lr}
f\left(e_{i}\right)=2 i & \text { for } i=1,2, \cdots, n \\
f\left(e_{i}^{\prime}\right)=4 n+2 i & \text { for } i=1,2, \cdots, n \\
f\left(E_{i}\right)=2 n+2 i & \text { for } i=1,2, \cdots, n
\end{array}
$$

So, the vertex labels will be

$f^{*}\left(v_{1}\right)=\left[f\left(e_{1}\right)+f\left(e_{n}\right)+f\left(E_{1}\right)\right] \bmod (6 n)=4 n+4$

$f^{*}\left(v_{i}\right)=\left[f\left(e_{i}\right)+f\left(e_{i-1}\right)+f\left(E_{n-i+2}\right)\right] \bmod (6 n)=(2 i+4 n+2) \bmod (6 n) i=2,3, \cdots, n$

Hence, the labels of the vertices $v_{1}, v_{2}, \cdots, v_{n}$ will be $4 n+4,4 n+6, \cdots, 0,2$ respectively.

Also, $f^{*}\left(v_{1}^{\prime}\right)=\left[f\left(e_{1}^{\prime}\right)+f\left(e_{n}^{\prime}\right)+f\left(E_{1}\right)\right] \bmod (6 n)=12 n+4 \bmod (6 n)=4$

$$
\begin{aligned}
f^{*}\left(v_{i}^{\prime}\right) & =\left[f\left(e_{i}^{\prime}\right)+f\left(e_{i-1}^{\prime}\right)+f\right] \bmod (6 n) \quad i=2,, \cdots, n \\
& =(2 i+12 n+2) \bmod (6 n)=2 i+2 \quad i=2,3, \cdots, n
\end{aligned}
$$

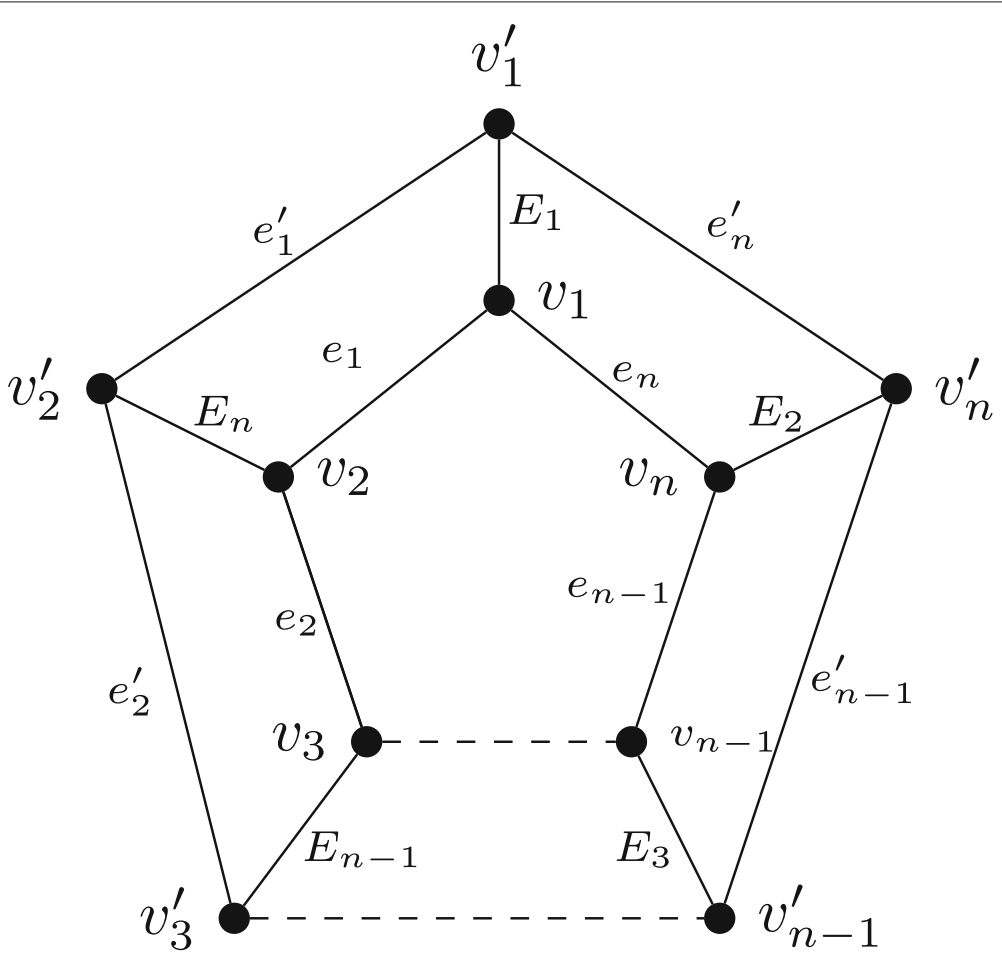

Fig. $18 \prod_{n}$ with ordinary labeling 

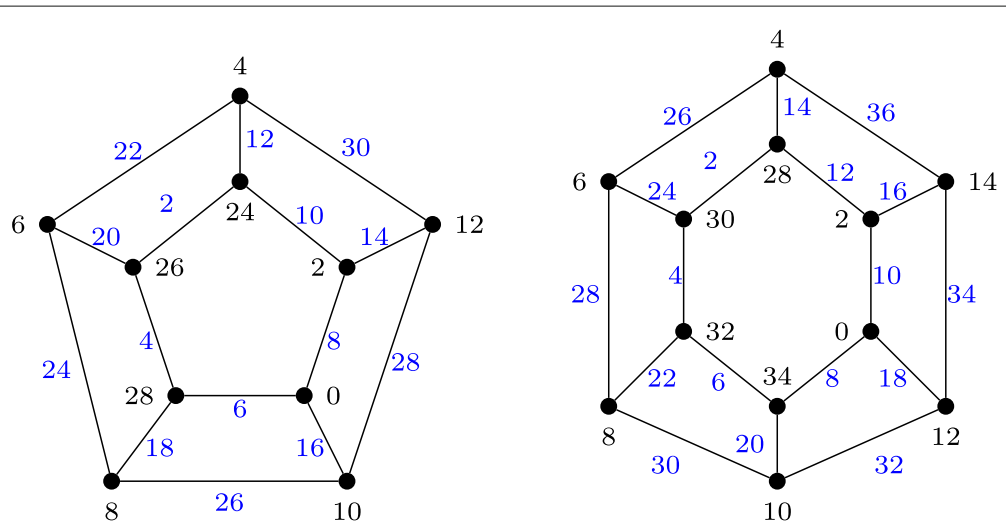

Fig. 19 An edge even graceful labeling of prism graphs $\prod_{5}$ and $\prod_{6}$

Hence, the labels of the vertices $v_{1}^{\prime}, v_{2}^{\prime}, \cdots, v_{n}^{\prime}$ are $4,6,8, \cdots, 2 n, 2 n+2$ respectively. Overall, the vertices are even and different. Thus, the prism graph $\prod_{n}$ is an edge even graceful graph.

Illustration: In Fig. 19, we present an edge even graceful labeling of of prism graphs $\prod_{5}$ and $\prod_{6}$.

The flower graph $\operatorname{FL}(n)(n \geq 3)$ is the graph obtained from a helm $H_{n}$ by joining each pendant vertex to the center of the helm.

Theorem 4 The flower graph $F L(n)(n \geq 4)$ is an edge even graceful graph.

Proof In the flower graph $\mathrm{FL}(n)(n \geq 4)$, we have $p=2 n+1$ and $q=4 n$. Let $\left\{v_{0}, v_{1}, v_{2}, \cdots, v_{n}, v_{1}^{\prime}, v_{2}^{\prime}, \cdots, v_{n}^{\prime}\right\}$ be the vertices of $\operatorname{FL}(n)$ and

$\left\{e_{1}, e_{2}, e_{3}, \cdots, e_{3 n}, E_{1}, E_{2}, E_{3}, \cdots, E_{n}\right\}$ be the edges of $\mathrm{FL}(n)$ as in Fig. 20.

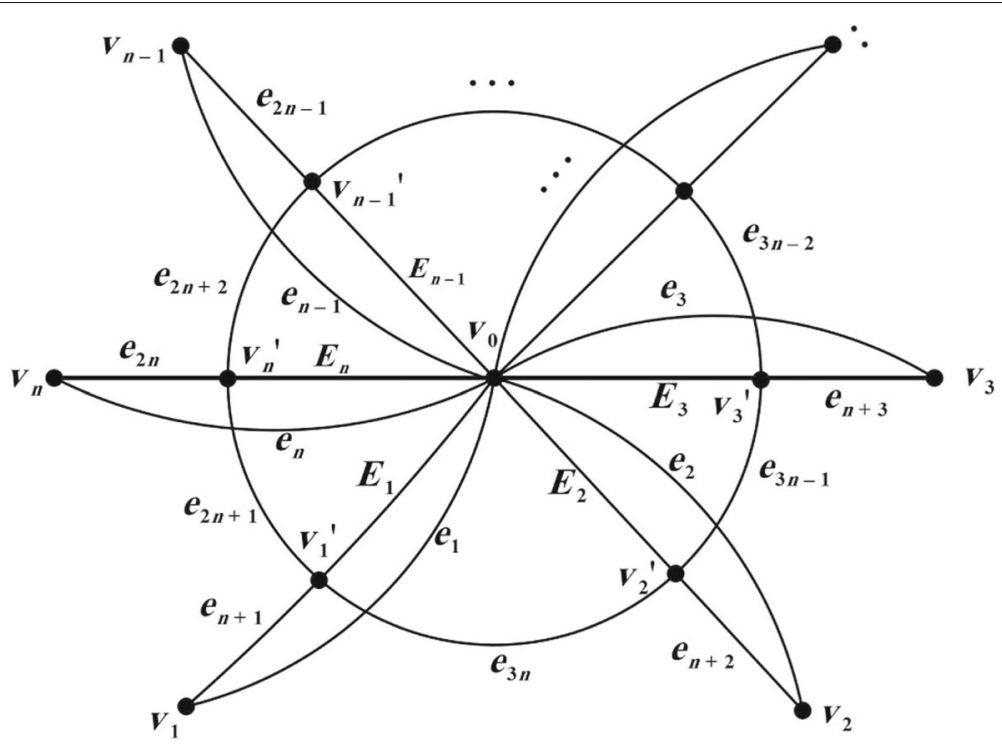

Fig. 20 The flower graph $F L(n)$ with ordinary labeling 


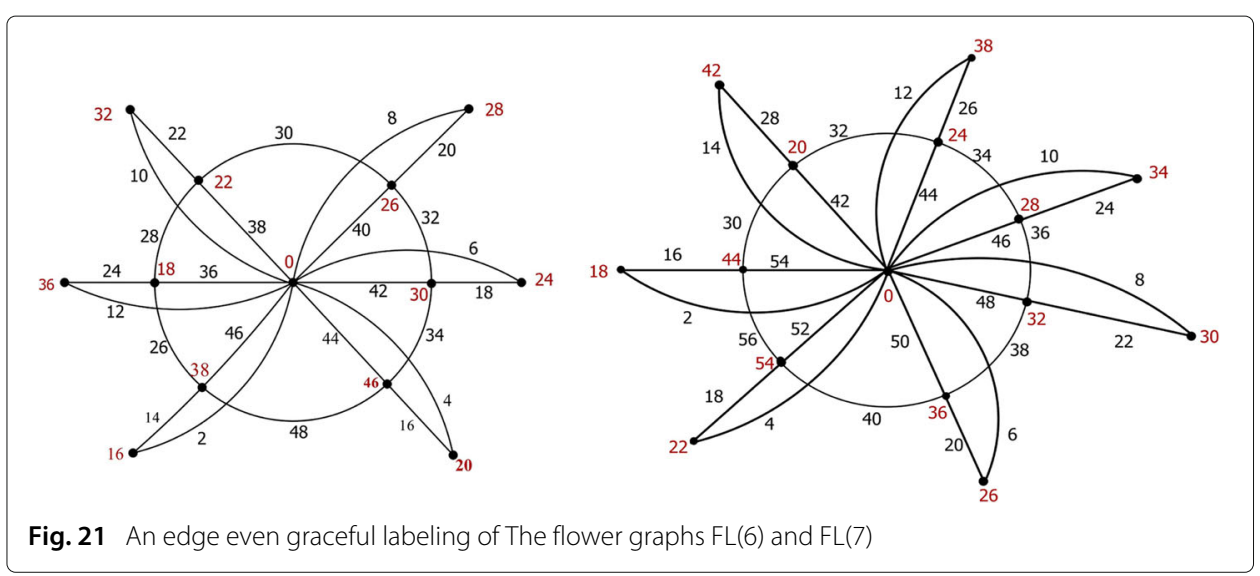

First, define the mapping $f: E(F l(n)) \rightarrow\{2,4, \cdots, 8 n\}$ as the following:

$$
\begin{aligned}
& f\left(E_{i}\right)=8 n-2 i \quad \text { for } i=1,2, \cdots, n \text { and } \\
& f\left(e_{i}\right)= \begin{cases}2 i & \text { if } 1 \leq i \leq 3 n-1 \\
8 n & \text { if } i=3 n\end{cases}
\end{aligned}
$$

Then, the induced vertex labels are

$$
\begin{aligned}
f^{*}\left(v_{0}\right) & =\left[\sum_{i=1}^{n}\left(f\left(e_{i}\right)+f\left(E_{i}\right)\right] \bmod (8 n)=0\right. \\
f^{*}\left(v_{i}\right) & =\left[f\left(e_{i}\right)+f\left(e_{n+i}\right)\right] \bmod (8 n)=2 n+4 i, \quad i=1,2, \cdots, n \\
f^{*}\left(v_{1}^{\prime}\right) & =\left[f\left(e_{3 n}\right)+f\left(e_{2 n+1}\right)+f\left(e_{n+1}\right)+f\left(E_{1}\right)\right] \bmod (8 n)=6 n+2 \\
f^{*}\left(v_{2}^{\prime}\right) & =\left[f\left(e_{3 n}\right)+f\left(e_{3 n-1}\right)+f\left(e_{n+2}\right)+f\left(E_{2}\right)\right] \bmod (8 n)=8 n-2 \\
f^{*}\left(v_{i}^{\prime}\right) & =\left[f\left(e_{3 n-i+1}\right)+f\left(e_{3 n-i+2}\right)+f\left(e_{n+i}\right)+f\left(E_{i}\right)\right] \bmod (8 n), \quad 3 \leq i \leq n \\
& =[6(n+1)-4 i] \bmod (8 n) \quad 3 \leq i \leq n
\end{aligned}
$$

Overall, all the vertex labels are even and distinct which complete the proof.

Illustration: In Fig. 21, we present an edge even graceful labeling of of the flower graphs FL(6)and FL(7).

\section{Acknowledgments}

I am so grateful to the reviewers for their valuable suggestions and comments that significantly improved the paper.

Funding

Not applicable.

\section{Availability of data and materials}

Not applicable.

\section{Authors' contributions}

The author read and approved the final manuscript.

\section{Competing interests}

The author declares that he has no competing interests.

\section{Publisher's Note}

Springer Nature remains neutral with regard to jurisdictional claims in published maps and institutional affiliations.

Received: 10 January 2019 Accepted: 22 February 2019

Published online: 09 July 2019 


\section{References}

1. Rosa, A.: Certain valuations of the vertices of a graph; Theory of Graphs (Internat. Symp, Rome, July 1966). Gordan and Breach, New York (1967). Paris, France

2. Gallian, J. A.: A Dynamic survey of graph labeling. The Electronic Journal of Combinatorics (2015). http://link.springer com/10.1007/978-1-84628-970-5

3. Daoud, S. N.: Edge odd graceful labeling of some path and cycle related graphs. AKCE International Journal of Graphs and Combinatorics. 14, 178-203 (2017). http://dx.doi.org/10.1016/j.akcej.2017.03.001

4. Seoud, M. A., Salim, M. A.: Further results on edge-odd graceful graphs. Turkish J. Math. 40(3), 647-656 (2016). https:// journals.tubitak.gov.tr/math/

5. Elsonbaty, A., Daoud, S. N.: Edge even graceful labeling of some path and cycle related graphs. Ars Combinatoria. 130(2), 79-96 (2017)

6. Bondy, J. A., Murty, U. S.: Graph Theory. Springer (2008). http://link.springer.com/10.1007/978-1-84628-970-5

\section{Submit your manuscript to a SpringerOpen ${ }^{\circ}$} journal and benefit from:

- Convenient online submission

Rigorous peer review

- Open access: articles freely available online

- High visibility within the field

- Retaining the copyright to your article

Submit your next manuscript at $\boldsymbol{\text { springeropen.com }}$ 